\title{
Fundo Público e o financiamento das Políticas Sociais no Brasil ${ }^{1}$
}

\author{
Public fund and the financing of social policies in Brazil
}

\section{Evilasio Salvador *}

\begin{abstract}
Resumo:
Este artigo discute a importância do fundo público na garantia dos direitos sociais. Para tanto, analisa o financiamento tributário do Estado brasileiro, destacando a expressiva regressividade da carga tributária. $O$ financiamento da política social pode ser analisado por três óticas: tributária, gestão financeira e financiamento indireto. $\mathrm{O}$ texto analisa e apresenta os dados do financiamento tributário das políticas sociais no período de 2001 a 2011. As despesas vinculadas são importantes para o Estado brasileiro garantir direitos, contudo, nem sempre o fato de garantir a vinculação significa que os gastos são feitos de forma a garantir a justiça social e a expandir os benefícios e serviços de forma universal, buscando erradicar as desigualdades sociais. Além disso, a regressividade tributária no financiamento das políticas sociais é um limitador da capacidade redistributiva do orçamento público.
\end{abstract}

Palavras-Chave: Fundo público. Políticas sociais. Tributos.

\begin{abstract}
:
This article discusses the importance of public fund in the guarantee of social rights. For both, it analyzes the tax funding of the Brazilian State, highlighting the expressive regressivity of the tax burden. The financing of social policy can be analyzed by three optics: tax, financial management and indirect financing. The text analyzes and displays the data from tax funding of social policies in the period 2001 to 2011. The costs involved are important for the brazilian State guarantee rights, however, not always the fact to ensure the linking means that the expenditures are made in such a way as to ensure social justice and to expand the benefits and services of universal way, seeking to eradicate the social inequalities. In addition, the regressivity tax financing social policies and a limiter of redistributive capacity of the public budget.
\end{abstract}

Keywords: Public fund. Social policies. Taxes.

\footnotetext{
${ }^{1}$ Apresentado no I simpósio orçamento público e políticas sociais, no dia 10 de abril de 2012, na Universidade Estadual de Londrina (UEL). Este artigo integra a pesquisa Financiamento Tributário da Política Social no PósReal, e conta com apoio financeiro do CNPq.

* Economista, mestre e doutor em Política Social. Professor do Departamento de Serviço Social e do Programa de Pós-Graduação em Política Social da Universidade de Brasília (UnB).E-mail: evilasioss@unb.br
} 


\section{Introdução}

No capitalismo ocorre uma disputa na sociedade por recursos do fundo público no âmbito do orçamento estatal. O orçamento público é um espaço de luta política, com as diferentes forças da sociedade, buscando inserir seus interesses. Os interesses dentro do Estado Capitalista são privados e, a partir da década de 1980, há um domínio hegemônico do capital financeiro. Sob o comando das políticas neoliberais foi esgarçada a liberalização financeira com o enfraquecimento do Estado e da proteção social, sob o efeito dos juros do serviço da dívida, potencializando a crise estrutural do capitalismo.

O orçamento público é que garante concretude à ação planejada do Estado e espelha as prioridades das políticas públicas que serão priorizadas pelo governo. O fundo público deve assegurar recursos suficientes para o financiamento das políticas sociais. Contudo, não basta a análise de como os recursos são alocados, uma questão fundamental é como as políticas públicas são financiadas, ou seja, sobre quem recai o financiamento do Estado?

Este artigo tem por objetivo discutir a importância do fundo público na garantia dos direitos sociais, além disso, o texto analisa o financiamento tributário do Estado brasileiro, destacando a expressiva regressividade da carga tributária. Por fim, apresentam-se três formas de analisar o financiamento da política social: pela ótica tributária, pela gestão financeira e pelo financiamento indireto. Apresenta-se de forma ilustrativa uma análise do financiamento tributário das políticas sociais no período de 2001 a 2011.

\section{Fundo Público e Orçamento Público: a importância para garantir direitos}

No capitalismo contemporâneo, o fundo público exerce uma função ativa nas políticas macroeconômicas, sendo essencial tanto na esfera da acumulação produtiva quanto no âmbito das políticas sociais. O fundo público tem papel relevante para a manutenção do capitalismo na esfera econômica e na garantia do contrato social. $\mathrm{O}$ alargamento das políticas sociais garante a expansão do mercado de consumo, ao mesmo tempo em que os recursos públicos são financiadores de políticas anticíclicas nos períodos de refração da atividade econômica. 
No Brasil, o fundo público ganhou contornos restritivos, tanto pela ótica do financiamento como pela dos gastos sociais, muito aquém das já limitadas conquistas da socialdemocracia ocorrida nos países desenvolvidos. Até mesmo as "reformas" realizadas por dentro do capitalismo central não lograram o mesmo êxito em nosso país, uma vez que a estruturação das políticas sociais foi marcada por componentes conservadores, que obstaculizaram avanços mais expressivos nos direitos da cidadania.

Para Francisco de Oliveira (1998, p. 19-20), "o fundo público, em suas diversas formas, passou a ser o pressuposto do financiamento da reprodução da força de trabalho, atingindo globalmente toda a população por meio dos gastos sociais".

De acordo com Behring (2004, p. 164):

[...] há no argumento de Oliveira um elemento indiscutível: o lugar estrutural do fundo público no capitalismo contemporâneo, como expressão da sua maturidade e imensas contradições. A produção e a realização do valor vão requisitar que o Estado se aproprie de parcela bastante significativa da maisvalia socialmente produzida para assegurar as condições gerais de produção e reprodução; dentro desse processo comparece o desenvolvimento de políticas sociais como lugar relevante de alocação do fundo público, a pender, claro, da correlação de forças políticas e de elementos culturais em cada formação nacional.

Existe uma miríade de formas de gastos sociais e de financiamento, incluindo a questão da manutenção e da valorização dos capitais pela via da dívida pública. A formação do capitalismo seria impensável sem a utilização de recursos públicos, que, muitas vezes, funcionam como uma "acumulação primitiva". Nas palavras de Mészáros (2003, p. 29) "apesar de todos os protestos em contrário, combinando com fantasias neoliberais relativas ao 'recuo das fronteiras do Estado', o sistema do capital não sobreviveria uma única semana sem o forte apoio que recebe do Estado". Isto somente se torna possível apropriando parcelas crescentes da riqueza pública em geral, ou mais especificamente, os recursos públicos que tomam a forma estatal nas economias e sociedades capitalistas (OLIVEIRA, 1998).

O fundo público está presente na reprodução do capital nas seguintes formas:

i. Como fonte importante para a realização do investimento capitalista. No capitalismo contemporâneo, o fundo público comparece por meio de subsídios, de desonerações tributárias, por incentivos fiscais, por redução da 
base tributária da renda do capital como base de financiamento integral ou parcial dos meios de produção, que viabilizam a reprodução do capital.

ii. Como fonte que viabiliza a reprodução da força de trabalho, por meio de salários indiretos, reduzindo o custo do capitalista na sua aquisição.

iii. Por meio das funções indiretas do Estado, que no capitalismo atual garante vultosos recursos do orçamento para investimentos em meios de transporte e infraestrutura, nos gastos com investigação e pesquisa, além dos subsídios e renúncias fiscais para as empresas.

iv. No capitalismo contemporâneo, o fundo público é responsável por uma transferência de recursos sob a forma de juros e amortização da dívida pública para o capital financeiro, em especial para as classes dos rentistas (SALVADOR, 2010). ${ }^{2}$

O fundo público ocupa um papel relevante na articulação das políticas sociais e na sua relação com a reprodução do capital. A presença dos fundos públicos na reprodução da força de trabalho e gastos sociais é uma questão estrutural do capitalismo.

O fundo público envolve toda a capacidade de mobilização de recursos que o Estado tem para intervir na economia, seja por meio das empresas públicas, pelo uso das suas políticas monetária e fiscal, assim como pelo orçamento público. Uma das principais formas da realização do fundo público é por meio da extração de recursos da sociedade na forma de impostos, contribuições e taxas, da mais-valia socialmente produzida, portanto, conforme Behring (2010) é parte do trabalho excedente que se transformou em lucro, juro ou renda da terra, sendo apropriado pelo Estado para o desempenho de múltiplas funções.

Com isso, a expressão mais visível do fundo público é o orçamento público. No Brasil, os recursos do orçamento público federal são expressos na Lei Orçamentária Anual (LOA) aprovada pelo Congresso Nacional (Brasil, 2012). A LOA 2012 fornece pistas dos valores em disputa no fundo público brasileiro: $R \$ 2,257$ (dois trilhões, duzentos $\mathrm{e}$ cinquenta e sete bilhões de reais), deste orçamento, $\mathrm{R} \$ 655,49$ bilhões referem-se ao refinanciamento da dívida pública. Então o Orçamento Geral da União exceto

\footnotetext{
${ }^{2}$ O que vive da renda proveniente da aplicação de capitais no mercado financeiro.
} 
refinanciamento alcança o montante de $\mathrm{R} \$ 1,6$ trilhão, deste montante, $\mathrm{R} \$ 535,79$ bilhões destinam-se às políticas da seguridade social. Do total de $\mathrm{R} \$ 1.464,99$ bilhões dos orçamentos fiscal e da seguridade social, $\mathrm{R} \$ 3$ 365,45 bilhões serão destinados ao pagamento de juros e amortização da dívida pública, ou seja, 1/4 do orçamento público brasileiro é comprometido com a esfera financeira da economia.

No período 2000 a 2009, o fundo público transferiu o equivalente a $45 \%$ do PIB produzido em 2009 para o capital financeiro. De acordo com o Instituto de Estudos Socioeconômicos (2010), com esses recursos seria possível custear o Programa Bolsa Família durante 108 anos (mantido fixo o valor do benefício do programa de 2009). Ou, ainda, seria possível o governo federal custear a educação durante 40 anos, se mantido o mesmo valor gasto em 2009.

O estudo do orçamento deve ser considerado como um elemento importante para compreender a política social, pois é uma peça técnica que vai além da sua estruturação contábil, refletindo a correlação de forças sociais e os interesses envolvidos na apropriação dos recursos públicos, bem como a definição de quem vai arcar com o ônus do financiamento dos gastos orçamentários. O dimensionamento desses gastos permite compreender e mensurar a importância dada a cada política pública no contexto histórico da conjuntura econômica, social e política vivenciada no país.

O orçamento não se limita a uma peça técnica e formal ou a um instrumento de planejamento; ele é, desde suas origens, uma peça de cunho político, conforme Fabrício de Oliveira (2009), ou seja, ele serve para orientar as negociações sobre quotas de sacrifício sobre os membros da sociedade no tocante ao financiamento do Estado e é utilizado como instrumento de controle e direcionamento dos gastos. O autor ressalta que a decisão sobre os objetivos de gastos do Estado e a fonte dos recursos para financiálo não é somente econômica, mas principalmente são escolhas políticas, refletindo a correlação de forças sociais e políticas atuantes e que têm hegemonia na sociedade. Os gastos orçamentários definem a direção e a forma de ação do Estado nas suas prioridades de políticas públicas.

Assim, para Fabrício de Oliveira (2009), o orçamento deve ser visto como o espelho da vida política de uma sociedade, à medida que registra e revela, em sua estrutura de gastos e receitas, sobre que classe ou fração de classe recai o maior ou o menor ônus da 
tributação e as que mais se beneficiam com os seus gastos. De forma que não se restringe a uma peça técnica e instrumental de política econômica e de planejamento, por meio do qual o Poder Executivo procura cumprir determinado programa de governo ou viabilizar objetivos macroeconômicos. A escolha do programa a ser implementado pelo Estado e dos objetivos de política econômica e social reflete os interesses das classes, envolvendo negociações de seus representantes políticos, sendo que orçamento é expressão das suas reivindicações.

A Constituição Federal (CF) de 1988, ainda que tenha seus limites, contemplou avanços em alguns aspectos relacionados aos direitos da cidadania, sobretudo os direitos trabalhistas e sindicais, às políticas de previdência, assistência social e saúde, que vão edificar a seguridade social no país, aos direitos educacionais, entre outros. A efetivação dessas conquistas e a perspectiva da consolidação de um sistema de bem-estar social no Brasil deveriam implicar aporte prioritário e considerável de recursos no orçamento público, além da elaboração de um conjunto de legislações complementares. Contudo, esse direcionamento vai ser frustrado a partir da década de 1990, marcada pelo predomínio da ideologia neoliberal e da contrarreforma do Estado, em cenário claramente desfavorável à efetivação das mudanças propostas pela Carta Magna.

Para Pochmann (2004), os países centrais no pós-guerra privilegiaram a redistribuição da renda gerada por meio dos fundos públicos, com tributação sobre os mais ricos e transferências dos recursos dos fundos para os mais pobres. O Estado Social não tratou apenas de disponibilizar serviços sociais e garantir renda aos pobres, mas tratou principalmente de retirar das forças de mercado o monopólio da expansão econômica e da gestão sobre a força de trabalho.

Pela primeira vez, os ricos passaram a pagar impostos, especialmente com o mecanismo da progressividade sobre a renda e patrimônio, assim como a população pauperizada passou a ser beneficiada tanto pelo acesso aos serviços públicos básicos (educação, saúde, transporte e moradia) como pelos programas de garantia de renda para estudo (bolsa de estudos), aposentadoria (inatividade por velhice), situação de invalidez ocupacional (pensão para deficientes físicos e mentais e doenças profissionais) e condição de desemprego (seguro desemprego). 
Em resumo, consolidou-se uma nova estrutura secundária (fundo público) de redistribuição da renda, que veio a se sobrepor à já existente estrutura distributiva primária constituída pela própria dinâmica capitalista (lucros, juros, aluguéis de imóveis, salários e remunerações). Enquanto os ricos passaram a ser tributados consideravelmente (impostos sobre a renda, patrimônio e herança), foi possível formar fundos públicos capazes de financiar a transferência de renda para a população de menor rendimento, permitindo reduzir a pobreza, o desemprego e a desigualdade social no centro do capitalismo mundial (POCHMANN, 2004, p. 5-6).

Contudo, este não é o caso do Brasil. Se tem uma definição para o fundo público no Brasil, particularmente para orçamento público, ela pode ser feita em uma única frase: o orçamento é financiado pelos pobres via impostos sobre o salário e por meio de tributos indiretos, sendo apropriado pelos mais ricos, via transferência de recursos para o mercado financeiro e acumulação de capital.

\section{Financiamento regressivo do orçamento público}

Uma das marcas da elevada concentração de renda e das desigualdades sociais no Brasil é o caráter regressivo da carga tributária. O sistema tributário brasileiro tem sido um instrumento a favor da concentração de renda, agravando o ônus fiscal dos mais pobres e aliviando o das classes mais ricas.

A correlação das forças sociais é importante para compreender a composição do fundo público no Brasil. Nessa perspectiva, O’Connor (1977, p. 203) considera as finanças tributárias como uma forma de exploração econômica que requer, por isso, análise de classe. Para o autor, "cada mudança importante no equilíbrio das forças políticas e classistas é registrada pela estrutura tributária. Dizendo-o de outro modo, os sistemas tributários são apenas formas particulares dos sistemas de classes". A defesa do imposto fortemente progressivo foi feita por Marx e Engels (1982), em 1848, no Manifesto Comunista, como forma de redistribuição da renda da burguesia.

No Brasil engendrou-se a partir do governo do presidente Fernando Henrique Cardoso (FHC) uma perversa concentração de renda via financiamento do orçamento público. Essa situação permaneceu inalterada no governo do presidente Lula. O último 
projeto de "reforma" tributária ${ }^{3}$ que se encontra na Câmara dos Deputados não altera a regressividade do sistema tributário e acaba com as fontes exclusivas de financiamento das políticas sociais, pois altera de forma substancial a vinculação das fontes de financiamento exclusivas das políticas da seguridade social (previdência, saúde e assistência social), educação e trabalho.

A arrecadação tributária de 2009 (BRASIL, 2009b) alcançou 35,39\% do PIB, isto é, R\$ 1,04 trilhão. ${ }^{4} A$ análise dos dados por base de incidência econômica dos tributos (consumo, patrimônio e renda) revela, que:

a) do montante de $\mathrm{R} \$ 1,04$ trilhão arrecadados, a maior parte dos tributos tem como base de incidência o consumo, totalizando $\mathrm{R} \$ 569,93$ bilhões, equivalentes a 54,90\% da arrecadação tributária das três esferas de governo;

b) quando se agrega a tributação incidente sobre o consumo com aquelas imputadas sobre a renda dos trabalhadores, fica revelado que o Estado brasileiro é financiado pelos trabalhadores assalariados e pelas classes de menor poder aquisitivo que são responsáveis por 65,58\% das receitas arrecadadas pela União, estados, Distrito Federal e municípios;

c) quando se compara os impostos e contribuições incidentes sobre os lucros dos bancos aos impostos e às contribuições calculadas sobre a renda dos trabalhadores observa-se que enquanto as entidades financeiras pagaram $\mathrm{R} \$$ 22,64 bilhões em Contribuição Social sobre o Lucro Líquido (CSLL) e Imposto de Renda Pessoa Jurídica (IPRJ), os trabalhadores pagaram quase cinco vezes mais tributos diretos que os bancos (R\$ 110,86 bilhões);

d) a carga tributária sobre patrimônio tem participação irrisória sobre o montante de tributos arrecadados, 3,72\%, ou 1,23\% do PIB.

Um aspecto particular da tributação sobre a renda no Brasil é que nem todos os rendimentos tributáveis de pessoas físicas são levados obrigatoriamente à tabela progressiva do IR e sujeitos ao ajuste anual de declaração de renda. Enquanto a tributação dos salários obedece às quatro alíquotas estabelecidas na legislação, os rendimentos decorrentes de renda fundiária variam de $0,03 \%$ a $20 \%$, conforme o grau de

\footnotetext{
${ }^{3}$ Trata-se da Proposta de Emenda Constitucional (PEC) 233/2008, que “altera o Sistema Tributário Nacional e dá outras providências".

${ }^{4}$ Conforme pesquisa que coordenamos para o Sindifisco Nacional (2010).
} 
utilização da terra e área total do imóvel; e os rendimentos de aplicações financeiras têm alíquotas que variam entre $0,01 \%$ e $22,5 \%$, conforme o prazo e o tipo de aplicação, privilegiando os rentistas. Essa situação vigente no país evidencia uma maior tributação sobre as rendas derivadas do trabalho no capitalismo brasileiro do século XXI.

Essa falta de isonomia criou uma situação esdrúxula no país, com "poucos" contribuintes apresentando elevada renda tributável. A título de exemplo, das 23,5 milhões de declarações de ajuste de imposto de renda do ano-base de 2006 (exercício de 2007), apenas 5.292 contribuintes apresentaram rendimentos tributáveis acima $R \$ 1$ milhão (BRASIL, 2009b). Paradoxalmente, o número de milionários no país não para de crescer. Conforme revelou o levantamento da The Boston Consulting Group (BCG), o Brasil tinha, em 2008, 220 mil milionários, uma expansão de 15,7\% em relação ao ano anterior (WIZIACK, 2008). A fortuna desses milionários está estimada em aproximadamente US\$ 1,2 trilhão, o que equivale a praticamente metade do PIB brasileiro. Para o BCG, milionários são aqueles que têm mais de US\$ 1 milhão aplicado no mercado financeiro.

\section{Financiamento das Políticas Sociais}

A disputa pela expansão e consolidação dos direitos sociais enfrenta essas funções do fundo público, que são determinantes para o capitalismo, cuja maior expressão é a apropriação de parte importante dos recursos do orçamento público. Para tanto, uma das alternativas para enfrentar a perversa tradição do orçamento fiscal brasileiro, que historicamente serviu para a acumulação de capital, foi a vinculação de recursos para áreas sociais.

Os fundos sociais têm sua origem no Brasil na luta contra a ditadura e no processo constituinte para aprovação de uma legislação que, com base na Constituição Federal, assegura-se a ampliação dos direitos sociais (ROCHA, 2002). Nesse sentido, o modelo de fundos públicos buscado foi aquele com conselhos de composição paritária entre os representantes governamentais e não governamentais para acompanhar e fiscalizar políticas públicas, apesar de ainda hoje prevalecer um montante elevado de recursos que ficam "fora dos fundos" em relação às respectivas políticas, pois ao criar um fundo vinculam-se receitas para a execução de determinados programas de trabalho. Por 
exemplo, cerca de $1 / 4$ dos recursos liquidados ${ }^{5}$ nas funções saúde, previdência e assistência social não passam pelos respectivos fundos sociais dessas políticas.

Hoje as principais vinculações existentes na Constituição Federal ${ }^{6}$ são: a) aplicação de no mínimo $18 \%$ das receitas dos impostos para a manutenção e ao desenvolvimento do ensino; b) as contribuições sociais elencadas no art. 195, que são exclusivas para o financiamento do orçamento da seguridade social; c) o gasto mínimo em ações e serviços públicos de saúde corrigidos anualmente pela variação nominal do PIB (EC 29); d) recursos aos estados e municípios, por meio do Fundo de Participação dos Estados e do Distrito Federal (FPE) e do Fundo de Participação dos Municípios (FPM); e) $60 \%$ da Contribuição PIS/Pasep são destinadas ao Fundo de Amparo ao Trabalhador (FAT) para custear o seguro-desemprego, o abono salarial e programas como treinamento e requalificação da mão-de-obra e $40 \%$ são repassadas ao BNDES para financiar programas de desenvolvimento econômico; f) a Contribuição de Intervenção no Domínio Econômico (Cide) é destinada ao custeio de programas de infraestrutura.

Algumas dessas despesas, destinadas aos direitos sociais (seguridade social, segurodesemprego e educação) no orçamento público, são obrigatórias e provocam a reação conservadora, que reclama do "engessamento" do orçamento público. ${ }^{7}$ Pelas despesas obrigatórias, a União é obrigada a executar por determinação constitucional ou de lei, não podem ser contingenciadas para realizar superávit primário. Em geral, são sempre as primeiras das listas de "reformas", que provavelmente serão assunto predominante no próximo governo.

Destacam-se nas despesas obrigatórias: i) benefícios previdenciários do Regime Geral de Previdência Social (RGPS); ii) benefícios concedidos pela Lei Orgânica da Assistência Social (LOAS) e pela Renda Mensal Vitalícia (RMV), em extinção, que determinam o pagamento de um salário mínimo de benefício mensal à pessoa portadora de deficiência e ao idoso que viva em família cuja renda mensal per capita seja inferior a

\footnotetext{
${ }^{5}$ De acordo com os dados do Sistema Integrado da Administração Financeira (SIAFI), disponibilizados pelo Sistema Siga do Senado Federal, no período de 2004 a 2009, do montante de R\$ 2,1 trilhões (deflacionados pelo IGP-DI) liquidados nas funções assistência social, previdência social e saúde; $R \$ 464,54$ bilhões passaram "por fora" dos fundos públicos sociais dessas políticas.

${ }^{6}$ Uma lista mais detalhada pode ser vista em Brasil (2003).

${ }^{7}$ Por exemplo, o estudo de Mendes (2009).
} 
1⁄4 do salário mínimo; iii) o abono salarial e o seguro desemprego; iv) gastos mínimos com saúde.

Os efeitos da vinculação orçamentária às políticas sociais específicas asseguram os gastos mínimos em políticas de saúde e educação também no âmbito dos municípios e dos estados. Arretche (2010) destaca na gestão das políticas sociais a existência de dois tipos de políticas descentralizadas: a) reguladas em que a legislação e a supervisão federal colocam limites na autonomia decisória dos governos subnacionais, assegurando assim gastos orçamentários obrigatórios em determinadas políticas sociais; e b) não reguladas que são aquelas nas quais a execução das políticas sociais está associada à autonomia das decisões dos governos locais.

O corolário da legislação pós-Constituição é que pelo menos $40 \%$ das receitas municipais devem ser alocadas nas áreas de saúde e educação, 25\% para educação e 15\% para saúde, respectivamente. Enquanto as políticas não reguladas, ou seja, sem a vinculação de gastos e receitas, como aquelas relacionadas ao desenvolvimento urbano (habitação e saneamento) padecem da vontade do governante na alocação orçamentária, não sendo políticas nem universais e nem regulares (ARRETCHE, 2010). Tal situação é rotina no orçamento federal, com as políticas sociais que dependem dos gastos discricionários apresentando uma baixa execução orçamentária, ${ }^{8}$ destacadamente: habitação, saneamento, urbanismo e direitos da cidadania. ${ }^{9}$ Desta forma, os gastos orçamentários com previdência, assistência social, saúde, educação e trabalho conseguem preservar a sua execução, pois têm a maior parte dos recursos de natureza obrigatória e vinculada (SALVADOR, 2010).

As despesas vinculadas são importantes despesas do Estado brasileiro para garantir direitos, contudo, nem sempre o fato de garantir a vinculação significa que os gastos são feitos de forma a garantir a justiça social e a expandir os benefícios e serviços de forma universal, buscando erradicar as desigualdades sociais.

Um exemplo dessa situação é o que ocorre na execução do orçamento da seguridade social. Em 2009, os recursos exclusivos do orçamento da seguridade social

\footnotetext{
${ }^{8}$ Refere-se à comparação das dotações orçamentárias autorizadas com os recursos que foram liquidados no Orçamento Geral da União. Ver nesse sentido tabela 6, disposta na obra de Salvador (2010, p. 187).

${ }^{9} \mathrm{Na}$ função direitos da cidadania no orçamento público estão, entre outras, as despesas relacionadas ao sistema nacional de proteção da criança e do adolescente, a gestão dos direitos humanos, da política nacional de juventude.
} 
financiaram, além das funções típicas da seguridade social (previdência, assistência social e saúde), outras 24 funções orçamentárias. Do montante de $R \$ 4$ 436, 22 bilhões, liquidados no orçamento da seguridade social, ${ }^{10} 10,73 \%$ (R\$ 46, 80 bilhões) não foram aplicados nas funções: assistência social, previdência social e saúde. A maior parte dos recursos $(60,37 \%)$ foi executada na função Trabalho e se destinou ao pagamento do benefício do seguro-desemprego. Contudo, outra parcela expressiva dos recursos (R\$ 18,5 bilhões), liquidados nas demais funções, refere-se ao pagamento de assistência medica e odontológica aos servidores, empregados e seus dependentes, o que contraria a diretriz constitucional de universalidade da saúde e deveriam ser pagos com recursos fiscais. Além disso, em 2009, a Desvinculação das Receitas da União (DRU) desviou R\$ 39,1 bilhões ${ }^{11}$ das políticas da seguridade social para acumulação de capital, por meio do orçamento fiscal. Desde a entrada em vigor da DRU, em 2000, já foram surrupiados da Seguridade Social mais de R\$ 300 bilhões (SALVADOR, 2010).

O financiamento da política social pode ser estudado por três óticas: a) pela ótica tributária que permite verificar o caráter progressivo ou regressivo das fontes de financiamento da política social, ponto fundamental para averiguar se a proposta sugere de fato uma redistribuição de renda ${ }^{12}$; b) pela análise da gestão financeira dos recursos, o que permite analisar as decisões no campo político-administrativo da política, a descentralização, assim como o controle democrático do orçamento; e c) pela identificação das renúncias tributárias, isto é, o financiamento indireto da política social.

Uma análise pela ótica tributária das três políticas sociais (previdência, assistência social e saúde) que integram a seguridade social revela que a estrutura do sistema tributário brasileiro rebate diretamente nas fontes de financiamento da seguridade social. Um olhar sobre o financiamento da seguridade social, no período de 2000 a 2007, identificando as bases econômicas de incidência tributária (renda, consumo e patrimônio), que compuseram o custeio das três políticas da seguridade revela uma estrutura tributária regressiva, confirmando as características presentes no sistema tributário brasileiro. O resultado apresentado, com base na média anual das fontes de

\footnotetext{
${ }^{10}$ Referem-se aos recursos orçamentários executado na esfera 2, conforme dados extraídos do sistema Siga Brasil.

${ }^{11}$ Dados extraídos do Relatório resumido da execução orçamentária do governo federal e outros demonstrativos, da Secretaria do Tesouro Nacional (BRASIL, 2009a).

${ }^{12}$ Os dados analisados neste artigo foram extraídos do sistema Siga Brasil.
} 
financiamento da seguridade social, no período de 2000 a 2007, em valores constantes, revela que os tributos diretos responderam por $30,87 \%$, dos quais somente $6,88 \%$ referem-se à tributação direta da renda do capital. Isto significa que os próprios beneficiários da seguridade social, pagam direta ou indiretamente seus benefícios (SALVADOR, 2010).

As ações governamentais na área da assistência social são realizadas com recursos do orçamento da seguridade social, previstos no artigo 195 da CF, além de outras fontes (art. 204). Vale registrar que a assistência social vem aumentando sua participação no orçamento da seguridade social evoluindo de 3,76\% (2000) para 9,27\% (2010). Em 2010, do montante de $\mathrm{R} \$ 39,1$ bilhões liquidados na função 8 (assistência social) do orçamento, 39\% estiveram sob a responsabilidade da Unidade Orçamentária (UO) Ministério do Desenvolvimento Social e Combate à Fome (MDA), sendo que $92 \%$ dos recursos foram destinados ao Programa Bolsa Família (PBF). Já na UO Fundo Nacional da Assistência Social (FNAS), que ficou responsável por $61 \%$ dos recursos da assistência social, $96 \%$ do orçamento foram liquidados no programa "Proteção Social Básica", que é responsável pelo pagamento do Benefício de Prestação Continuada (BPC) e da Renda Mensal Vitalícia (RMV) (SALVADOR, 2011).

A execução orçamentária da função assistência social por fontes de financiamento no período de 2001 a 2011. Ao analisar a participação de cada uma das fontes, observa-se a elevada concentração da Contribuição para o Financiamento da Seguridade Social (COFINS), responsável por mais de $77,12 \%$ no período avaliado. Esse tributo visa atender programas sociais do governo e tem sua incidência sobre a receita e o faturamento das empresas, sendo passível de ser transferido para os preços de bens e serviços, ou seja, a política de assistência social é financiada pelos próprios beneficiários desta, conferindo um caráter regressivo a este tributo.

Na previdência social, a principal fonte de financiamento é a Contribuição dos Empregadores e Trabalhadores para a Seguridade Social (CETSS), que é conhecida como contribuição sobre "folha de pagamento". Cerca de $2 / 3$ do montante advém da contribuição dos empregadores e 1/3 dos empregados, excluindo-se do cálculo as outras contribuições previdenciárias. Em 2011, 66\% do financiamento da previdência social veio dessa contribuição. No caso dos empregadores, a contribuição previdenciária compõe os 
encargos sociais das empresas, e, muitas vezes, são repassados aos preços dos bens e serviços vendidos, podendo-se constituir um tributo sobre o consumo. A regressividade existe também no lado das contribuições dos trabalhadores, em função da existência do teto de contribuição.

O financiamento da política de saúde enfrenta problemas desde o início do Sistema Único de Saúde (SUS), cujo ápice foi a crise em 1993, quando o Ministério da Saúde teve de tomar recursos emprestados do Fundo de Amparo ao Trabalhador (FAT). A análise tributária revela que foram três fontes que tiveram participação relevante no financiamento da saúde no período de 2001 a 2011. A principal foi a contribuição social sobre lucro das empresas, que respondeu por $35,31 \%$ no período. Trata-se de um tributo direto sobre a renda do capital. O segundo tributo foi a COFINS, que representou $28,66 \%$ no período. Depois a Contribuição Provisória sobre a Movimentação ou Transmissão de Valores e de Créditos e Direitos de Natureza Financeira (CPMF), extinta em 2007, que respondeu por $20,32 \%$ do financiamento da saúde nos últimos dez anos. A CPMF era, em parte, um tributo proporcional sobre a renda das pessoas e uma parte significativa era repassada para o consumo, pois as empresas respondiam por $70 \%$ da arrecadação desse tributo.

A política de educação é uma das únicas políticas sociais executadas no orçamento fiscal da União, como recursos vinculados e de gastos obrigatórios, o que vem garantido uma relativa estabilidade nas fontes orçamentárias ao longo dos anos. Como lembrado por Castro (2004), o financiamento público da educação no Brasil foi consolidado na CF de 1988 e na Lei de Diretrizes e Bases da Educação Nacional (LDB), que atribuíram à União, aos estados, ao DF e aos municípios a responsabilidade pela administração do sistema educacional brasileiro, consagrando a existência de três sistemas de ensinos público, tendo como fundamento o regime de colaboração entre essas instâncias federadas.

No período de 2001 a 2011, em média, 57\% dos recursos que financiam a educação no âmbito da União são provenientes de impostos, particularmente, a fonte "recursos destinados à manutenção e desenvolvimento do ensino (MDE)", ou seja, da arrecadação dos impostos, líquidos de transferências constitucionais. Esta fonte é uma garantia constitucional estabelecida no artigo 212 da CF, que determina a aplicação de no mínimo $18 \%$ dos impostos na manutenção e desenvolvimento do ensino. 
A política social-trabalho é financiada, em grande parte, via Fundo de Amparo ao Trabalhador (FAT), que é responsável pelo principal programa executado no âmbito do orçamento que é "integração das políticas públicas de emprego e renda." A principal fonte tributária que financia a política social de trabalho no Brasil é a contribuição social PIS/Pasep (65\%), que é destinada ao FAT. A base de incidência do PIS/Pasep é o faturamento das empresas, sendo repassados via preços e serviços ao consumo, isto é, uma fonte de financiamento regressiva, que é paga por toda população, principalmente a mais pobre. Contudo, o acesso aos principais benefícios que são pagos por esta fonte: seguro-desemprego e abono salarial é restrito somente aos trabalhadores inseridos em relações formais de trabalho. Nesse período, $26,77 \%$ do financiamento da política de trabalho foi feita por recursos financeiros diretamente arrecadados, cuja origem dos recursos financeiros são as aplicações no mercado financeiro do FAT. Isso revela um paradoxo, pois o financiamento da política social do trabalho no Brasil depende das aplicações financeiras e, portanto, de elevadas taxas de juros, que é fruto da política monetária que impede o crescimento e a geração de empregos no país.

Um exemplo de uma análise pela ótica da gestão financeira pode ser feito na política de assistência social. O Sistema Único da Assistência Social (SUAS) propôs um modelo de financiamento que indica que a participação da população deve ser priorizada, assim como a descentralização político-administrativa e o controle social, contribuindo para um padrão mais transparente e mais próximo de uma gestão democrática. De acordo com Tavares (2009), o modelo de financiamento a partir do SUAS rompe com a lógica de custeio dos serviços socioassistenciais mediante relação convenial baseada no estabelecimento de valores per capita, ou seja, os valores eram repassados pelo número de atendimentos e não na conformação dos serviços.

Apesar das orientações do SUAS de cofinanciamento com estados e municípios na política de assistência social, a União permanece respondendo por mais de $3 / 4$ do financiamento da política de assistência social. Um desafio a ser vencido é o estabelecimento de um percentual mínimo a ser aplicado na política de assistência social pelos estados e municípios.

O financiamento indireto das políticas sociais pode ser analisado a partir do chamado gasto tributário. A Receita Federal identifica o gasto tributário a partir das 
desonerações tributárias e também pela avaliação de quais desonerações são gastos indiretos e passíveis de substituição por gastos diretos. De acordo com a Receita Federal (BRASIL, 2011), os gastos tributários alcançaram o montante de $\mathrm{R} \$ 113,00$ bilhões no último ano, ou seja, 3,42\% PIB. Somente na política de assistência social alcançou R\$ 5 bilhões, um valor significativo, que não passa pelo controle social. Consiste num modelo de financiamento dos serviços socioassistenciais distinto do proposto pelo SUAS, prestado pela rede não governamental cujas características estão mais próximas da filantropia (COLIN, 2010).

Assim também ocorre com as políticas de educação e saúde. Que na prática significa uma transferência de recursos do fundo público para as empresas privadas do setor educacional e da área de saúde. No demonstrativo de gastos tributário que acompanha a Proposta de Lei Orçamentária Anual (PLOA) 2012, a Receita Federal (BRASIL, 2011) informa que as renúncias tributárias na área da saúde alcançaram $R \$ 19,8$ bilhões neste ano. Na política de educação o financiamento indireto alcança o total de $R \$$ R\$ 7 bilhões.

\section{Considerações finais}

O orçamento público não se limita a uma peça técnica e formal ou a um instrumento de planejamento, ele é, desde suas origens, uma peça de cunho político. No orçamento é que são definidas as prioridades de aplicação dos recursos públicos e a composição das receitas, ou seja, sobre quem vai recair o peso do financiamento tributário. Não se trata de uma escolha somente econômica, mas principalmente resultado de opções políticas, refletindo a correlação de forças sociais presente na sociedade.

A correlação da luta de classes no país, no contexto do neoliberalismo, foi desfavorável aos trabalhadores e decisiva para o predomínio dos impostos indiretos e regressivos na estrutura tributária. O sistema tributário foi edificado para privilegiar a acumulação capitalista e onerar os mais pobres e os trabalhadores assalariados, que efetivamente pagam a "conta". Eles são os maiores responsáveis pelo financiamento do Estado brasileiro, arcando com o ônus de mais de 2/3 das receitas arrecadadas pela União, estados, Distrito Federal e municípios. As aplicações financeiras são menos 
tributadas que a renda dos trabalhadores assalariados. O capital foi o maior ganhador do sistema tributário construído nos governos FHC e Lula. O sistema financeiro paga menos imposto que o restante da sociedade.

O orçamento público no capitalismo brasileiro é refém dos rentistas do capital financeiro, obstaculizando a construção de um sistema de proteção social universal. Os ricos neste país continuam não pagando impostos, pois suas rendas estão isentas da tributação. Ao mesmo tempo em que a maior parcela do orçamento é destinada ao capital portador de juros, por meio do pagamento de juros e amortização da dívida pública.

Nesse sentido, a consolidação e expansão das políticas sociais no orçamento público passam pela necessidade do atendimento em cada período fiscal ao princípio da demanda por direitos já regulamentados, irrestrito no caso dos direitos sociais expressos individualmente, e compatível no caso dos direitos expressos como demanda por bens coletivos. A consequência deste enunciado é a não existência de teto físico-financeiro aos orçamentos sociais, mas tão somente princípios fiscais compatíveis com os princípios da política social. $\mathrm{Na}$ prática, isso significa que o orçamento público deve atender prioritariamente aos direitos sociais, sem restrições financeiras que impeçam a sua consolidação e o seu avanço.

\section{Referências}

ARRETCHE, M. Federalismo e igualdade territorial: uma contradição em termos? Dados, Rio de Janeiro, v. 53, p. 587-620, 2010. Disponível em:

$<$ http://www.scielo.br/scielo.php?script=sci_arttext\&pid=S0011-52582010000300003>. Acesso em: 15 out. 2011.

BEHRING, E. R. Crise do capital, fundo público e valor. In: BOSCHETTI, I. et al. Capitalismo em crise, política social e direitos. São Paulo: Cortez, 2010. Parte 1.

BEHRING, E. R. Política social: notas sobre o presente e o futuro. In: BOSCHETTI, I. et al. (Org.). Política social: alternativas ao neoliberalismo. Brasília: UnB, 2004. p. 161-180.

BRASIL. Lei no 12.595 de 19 de janeiro de 2012. Estima a receita e fixa a despesa da união para o exercício financeiro de 2012. Brasília, 2012.

BRASIL. Ministério da Fazenda. Receita Federal. Demonstrativo dos gastos tributários 2012. Brasília, ago. 2011. 
BRASIL. Ministério da Fazenda. Secretaria do Tesouro Nacional. Relatório resumido da execução orçamentária do governo federal e outros demonstrativos. Brasília: Secretaria do Tesouro Nacional, 2009a.

BRASIL. Ministério do Planejamento. Orçamento e Gestão. Secretaria de Orçamento Federal. Vinculações de receitas dos orçamentos fiscais e da seguridade social e o poder discricionário de alocação dos recursos do Governo Federal. Brasília: SOF, 2003.

BRASIL. Presidência da República. Observatório da Equidade. Indicadores do sistema tributário nacional. Brasília: Presidência da República, $2009 \mathrm{~b}$.

CASTRO, J. Estrutura de financiamento público da educação no Brasil. Brasília: IPEA, 2004.

COLIN, D. A gestão e o financiamento da assistência social transitando entre a filantropia e a política pública. In: STUCHI, C.; PAULA, R.; PAZ, R. (Org.). Assistência social e filantropia: novo marco regulatório e o cenário contemporâneo de tensões entre o público e o privado. São Paulo: Giz, 2010.

INSTITUTO DE ESTUDOS SOCIOECONÔMICOS. Análise do PLDO 2011. Nota Técnica, Brasília, n. 166, maio 2010.

MARX, K.; ENGELS, F. Manifesto do partido comunista. In: BARATA-MOURA, E. (Org.). Obras escolhidas Marx e Engels. Lisboa: Edições Avante, 1982. t. 1, p. 95-136.

MENDES, M. Sistema orçamentário brasileiro: planejamento, equilíbrio fiscal e qualidade do gasto público. Caderno de Finanças Públicas, Brasília, n. 9, p. 57-102, dez. 2009.

MÉSZÁROS, I. O século XXI: socialismo ou barbárie? São Paulo: Boitempo, 2003.

O’CONNOR, J. USA: a crise do estado capitalista. Rio de Janeiro: Paz e Terra, 1977.

OLIVEIRA, F. Economia e política das finanças públicas: uma abordagem crítica da teoria convencional, à luz da economia brasileira. São Paulo: Hucitec, 2009.

OLIVEIRA, F. Os direitos do antivalor: a economia política da hegemonia imperfeita.

Petrópolis: Vozes, 1998.

POCHMANN, M. Proteção social na periferia do capitalismo: considerações sobre o Brasil. São Paulo em Perspectiva, São Paulo, v. 18, n. 2, p. 3-16, 2004.

ROCHA, P. Concepções dos fundos e seus impactos nas políticas sociais. In: MAGALHÃES JÚNIOR, J.; TEIXEIRA, A. C. (Org.). Fundos públicos e políticas sociais. São Paulo: Instituto Pólis, 2004. p. 85-92.

SALVADOR, E. Fundo público e seguridade social. São Paulo: Cortez, 2010.

SALVADOR, E. Orçamento da assistência social entre benefícios e serviços. In: VAZ, F. T.; MARTINS, F. J. (Org.). Orçamento e políticas públicas: condicionantes e externalidades. Brasília: ANFIP, 2011. p. 199-222. 
SINDIFISCO NACIONAL. Sistema tributário: diagnóstico e elementos para mudanças. Brasília: Sindifisco Nacional, 2010.

TAVARES, G. C. O financiamento da política de assistência social na era SUAS. In: BRASIL. Ministério de Desenvolvimento Social e Combate À Fome. Concepção e gestão da proteção social não contributiva no Brasil. Brasília: Ministério do Desenvolvimento Social e Combate à Fome, 2009.

WIZIACK, J. Brasil já possui 220 mil milionários, diz pesquisa. Folha de São Paulo, São Paulo, 5 ago. 2008. Disponível em:

<http://www1.folha.uol.com.br/folha/dinheiro/ult91u441681.shtml.>. Acesso em: 20 out. 2009. 